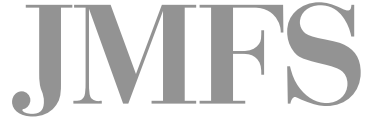

Journal of Management and Financial Sciences
Volume XI

Issue 33 (September 2018)

pp. 147-155

Warsaw School of Economics

Collegium of Management and Finance

Paweł Zagrajek, Adam Hoszman

Collegium of Management and Finance

Warsaw School of Economics

\title{
Impact of Ground Handling on Air Traffic Volatility
}

\begin{abstract}
Ground handling services constitute an important element of airline operations and significantly affect traffic stability and punctuality. In this article, the existing and potential impact of airline handling on air traffic volatility is reviewed from the point of view of airlines and ground operations. The issues of airline expectations towards ground handling agents (including handling rates, turnaround time, passenger services, and ramp services) are explored. In addition, the impact of an airline's schedule and the volatility of its operations on the performance and operational requirements of handling agents is discussed, including actions required by handling agents in response to the above challenges. The mechanism of how the volatility of an airline's schedule and its operations may impact the volatility of ground operations (directly and indirectly) is considered. The statistics of airline delays caused by ground operations are presented and discussed. The issue of the correctness of air traffic delays reporting by airlines is investigated.

Furthermore, this article investigates internal factors of ground handling agents and their impact on air traffic volatility. The existing and potential considerations discussed include staff management issues (in particular, employee rotation resulting in staff shortages and service quality, including punctuality), resources management, the ground service support equipment (including new developments aiming at limiting ground safety incidents), and their impact on performance.
\end{abstract}

Keywords: air traffic volatility, delays, on-time performance JEL Classification Code: R41 


\section{Introduction}

Delays in aircraft operations have been a more and more pending problem recently. As ground handling operations is one of the factors that may induce delays in aircraft operations, it is discussed and analyzed thoroughly in this paper [Zamkova, Prokop, Stolín, 2017, pp. 1799-1807]. The increase in the number of average delays observed especially at big airports proves that congestion has become a real problem at large international hubs. Research shows that at such airports delays associated with hubbing are almost entirely induced by hub airlines themselves [Mayer, Sinai, 2003, pp. 1194-1215], which makes it even more important to limit other delay factors, including ground handling. Containing primary delay factors will reduce reactionary delays. Considering that the latter constitute almost half of all delays in terms of total delay time in Europe, limiting primary delay causes may hamper propagation and help decrease overall delays [Wu, Wu, Feng, Zhang, Qiu, 2018].

\section{Ground handling on-time performance}

Ground handling services and operations represent both airside and landside operations aimed at servicing parked aircraft between two subsequent flights as well as processing passengers, their luggage and cargo. More specifically, passenger handling comprises many processes both before departure or upon arrival including: check-in services, baggage tags and screening processing, passenger transportation, PRM assistance, lost and found, baggage sorting, transportation and delivery, departure/gate service, unaccompanied minors, VIP services. Cargo handling and warehousing services may include special cargo, cargo transportation, de/consolidation, labelling, etc. Ramp services may comprise loading and unloading aircraft, push back, load control and flight coordination, water and toilet services, fueling, catering provision, cleaning, maintenance. The scope of services provided may vary depending on an airline and an airport it operates to/from.

Ground handling tasks may be carried out by various companies and parties, often involved in the activities taking place at the same time. Apart from activities of different companies, aircraft handling may be influenced or even interrupted by various parties including airport authorities, security service provider, board control or an airline itself. Apart from the on-time activity of different stakeholders, airport operational, security and safety procedures may also significantly impact ground handling operations. The infrastructure itself has also a great impact on ground handling performance. It comprises airport layout, airside and landside capacity, ramp configuration, baggage system, warehouse size, etc. The infrastructure issue may also include handling specific problems, for example the GSE equipment parking position, distance to resting rooms, etc. 
Most of ground handling tasks require specialized equipment called the Ground Support Equipment (GSE). This may include the usage of passenger steps or bridge, dollies, baggage carts, tractors, conveyor belts, toilet trucks, lavatory trucks, GPU, ASU, ACU, high loaders, ambulift, de-icing truck. This equipment must be available and reliable during the turnaround operations.

Each turnaround must also be serviced by an appropriate number of trained staff.

Moreover, each turnaround is a subject of rigid airline procedures regulated in the Ground Operations Manual (GOM) as well as other documents and procedures. Turnaround performance is also subject to strict timeframes and operating levels, often agreed and regulated in standard level agreements (SLAs).

The complexity of ground handling services as well as the environment of handling activities make ground handling operations vulnerable to operations disruptions and delays. Moreover, these operations are further exposed to disruptions due to operational circumstances at strategic, tactical and operating levels.

At the strategic level, an airline may negotiate a standard level agreement that requires performance which is difficult to be met in the future. This may contribute to occasional or permanent problems with schedule performance. Future ground handling operations may be also influenced by strategic airport decisions on airport infrastructure like the airside layout or GSE parking space.

Two elements may influence future ground operations performance at the tactical level:

Firstly, ground operations may be adversely impacted by schedule amendments. It is especially evident in the case of charter carriers. If such a change leads to a shift of operations from peak to off-peak hours or does not require extra resources to be provided, it may have a neutral or even positive effect on ground operations. However, if such a change makes it necessary to provide extra resources (staff or GSE equipment) it may lead to a situation that ground handling provider is not able to adhere to the new operational requirements in the required time. The more frequent the amendments or the closer to flight departure they are introduced, the more difficult it is for a ground handler to adapt to the new schedule. Consequently, the probability of temporary disturbances rises. Generally, it can be noticed that this proneness to schedule changes is strongly dependent on airlines' business models.

The amendment or development of the airport's or other stakeholders' operating procedures may further adversely impact ground handling operations. An example of such amendments are the regulations preventing passengers from queuing in the jet bridge.

The operational level brings another set of possible causes of delays. A delayed arrival of an aircraft from the previous flight may severely impede the ability of the ground handler to provide the staff and equipment to service the given aircraft. It may also adversely impact services of other aircraft.

The delay may be also caused by another service provider (e.g. catering, fuel, cargo transport from the warehouse) or subcontractor (e.g. cleaning). It should be emphasized that 
service provision by various provides may also lead to dilution of responsibility for on-time performance and consequently decrease the service quality, including on-time performance.

Ground handling delays may also be initiated by a decision of an airport's authority. For example, this may includethe gate/stand assignment as well as control and inspection activities.

It may also be a consequence of an airline's decision. For example,the crew may decide to remove some items of carry-on baggage and put it into the aircraft hold. If initiated at the late stage of turnaround, it may cause an overall delay.

Finally, a delay may be caused by the ground handling provider's internal problem. This may include a lack of staff or a human error, a lack of equipment or a system error.

Turnaround may also be adversely affected by extreme weather conditions. For example, aircraft position can be covered with snow, which would severely impact operations of the ground handler. The wind may limit the unloading process (under certain circumstances the hold cannot be opened).

As already explained, a delay caused by handling operations may be generated at various stages of passengers and aircraft service. Referring to IATA codes, it may comprise passenger and baggage processes (IATA delay code 11-13, 15-19), including a late check-in, a check-in error, boarding (discrepancies and paging, a missing checked-in passenger), a catering order (if placed by the handling operator), baggage processing (e.g. sorting), boarding/deboarding of passengers with reduced mobility.

Cargo and mail (codes 21-24, 26 and 27-29 applicable only to mail), including documentation problems, late positioning, late acceptance, inadequate packing, late preparation in the warehouse.

Aircraft and ramp handling (codes 31-39), including aircraft documentation problems (weight and balance, general declaration, pax manifest, etc.), loading/unloading (a lack of loading equipment, a lack of staff, an inappropriate process), cleaning, fueling, catering, ULD (if made unserviceable by the ground operator), other services (incl. water, toilet, push-back, etc.)

A delay may also be a result of aircraft damage by the ground operator (IATA code 52) including loading/off-loading damage, contamination, towing, etc.

Currently, the ground handling business faces several trends which may impact ground handlers' ability to meet on-time performance goals. The most evident trend is the dynamic evolution of airline business models followed by a requirement for the shortest possible turnaround time, the dynamic change in products and constant cost pressure on handling companies.

Contrary to the situation in the past when only low-cost carriers pressed for shortening turnaround times, currently airlines representing all business models tend to demand from ground service providers the shortest possible turnaround times. Consequently, ground times are planned according to most favorable conditions. The margin for an atypical situation is limited. In the case of longer deboarding, a difficult load, etc. these times are difficult or impossible to be met.

Cost pressure forces ground handlers to cut salaries, which in turn results in higher employees' rotation and possible shortages in staff. This situation is further worsened if there is an 
unfavorable situation on the job market ant it is difficult to find employees, which is currently the case on the Polish market. This situation may contribute to delays caused by a lack of staff or human errors. Moreover, cost constraints may prevent from modernization and purchases of new GSE equipment, which may lead to its lower reliability and contribute to delays.

Dynamic changes of products, for example a new baggage allowance policy, may also lead to significant operations disruptions, and consequently lead to delays. The most prominent example of such a situation are changes to airlines baggage policies.

Moreover, the ability of a ground handling company to provide on-time operations may be adversely affected by the continued increase inthe average aircraft capacity, especially when bigger aircraft are assigned the same gate as the smaller ones.

Ground handling on-time performance is also impeded by the increasing congestion of airports.

Several issues should be taken into consideration to respond to the current problems and future challenges in terms of on-time performance of ground handling operations. Firstly, there is a need for efficient dialogue between all parties involved.

As delays pose a more and more pending problem for all the parties active in the air transport sector, measures are taken in order to reduce delays and limit their impact on everyone concerned. One of such initiatives is Airport Collaborative Decision Making (A-CDM), which facilitates making decisions together by partners who want to improve their operational efficiency. This is done through information sharing by key actors involved in aircraft operations, i.e. airport operators, aircraft operators, ground handlers, air traffic control and the Network Manager [ACDM Impact Assessment]. As of April 2018, A-CDM is fully implemented in 26 airports across Europe [Eurocontrol]. The implementation of A-CDM has many benefits at both local and network scales, including:

- Increased peak departure rates at the runway;

- Improved take-off time predictabilityby $85 \%$ during adverse conditions;

- Improved ground handling resource utilization;

- Reduction in the number of late stands and gate changes;

- Improved management of and recovery from adverse conditions;

- Average taxi-out time savings between 0.25 and 3 minutes per departure;

- Average schedule adherence improvements between 0.5 and 2 minutes per flight;

- Reduction in the standard deviation of take-off accuracy from 14 to between 5 and 7 minutes [ACDM Impact Assessment].

The extension of A-CDM facility to other airports may further improve efficiency. It is estimated that the integration of Europe's 50 busiest airports should increase en-route capacity by $3.5-5.5 \%$. Moreover $40 \mathrm{CDM}$ airports could yield reductions of the average ATFM delay of 20-25\% [ACDM Impact Assessment]. The increase in efficiency will be achieved not only by including new (including smaller and non-EU) airports in the A-CDM scheme [Zanin, Belkoura, Yanbo, 2017, pp. 491-499] but also through extending this facility to new airport processes. 
Constant dialogue and exchange of information about operational performance between airlines and ground handling providers at all stages of their cooperation is another crucial factor supporting improvement in on-time performance.

Moreover, ground service providers have to consequently work on on-time and safety performance. These issues should be taken into consideration while budgeting, planning operations, purchasing equipment, staffing and training.

\section{Delay causes: Eurocontrol data analysis}

In order to find out to what extent ground handling operations influence delays of flights delay statistics were analyzed. The IATA provides a system of delay cause categories, which is also reflected in CODA delay groupings [Walker, 2016].

Delay causes are generally divided into primary and reactionary ones. With many factors that may primarily cause delays, there is further subdivision into the following categories and subcategories:

- Airline:

- Passenger and Baggage;

- Cargo and Mail;

- Aircraft and Ramp Handling;

- Technical and Aircraft Equipment;

- Damage to Aircraft \& EDP/Automated Equipment Failure;

- Other Airline Related Causes;

- Airport:

- ATFM due to Restriction at Destination Airport;

- Airport Facilities;

- Restrictions at Airport of Destination;

- Restrictions at Airport of Departure;

- En-Route:

- ATFM due to ATC En-Route Demand / Capacity;

- ATFM due to ATC Staff / Equipment En-Route;

- Governmental:

- Security and Immigration;

- Weather:

- Weather (other than ATFM);

- ATFM due to Weather at Destination;

- Miscellaneous:

- Miscellaneous.

Reactionary delays, on the other hand, are caused by a late arrival of an aircraft, crew, passengers or cargo. 
In this paper the emphasis is put on ground-handling-induced delays hence the "Aircraft and Ramp Handling" subcategory will be further analyzed. Handling-induced delays are analysed in two aspects - in terms of the average delay per flight as well as the share of a delay relative to other causes enumerated above.Figure 1 shows the distribution of primary delay causes (reactionary delays are excluded and their share is the complement of cumulative shares of all the causes to unity; it is 44 to 45 per cent of total delay causes depending on the year). All data presented in this section was provided by Eurocontrol/CODA and covers ca. $70 \%$ of commercial flights in the ECAC region in the 2012-2017 period.

Figure 1. Share of delays (in minutes) by causes (\%)

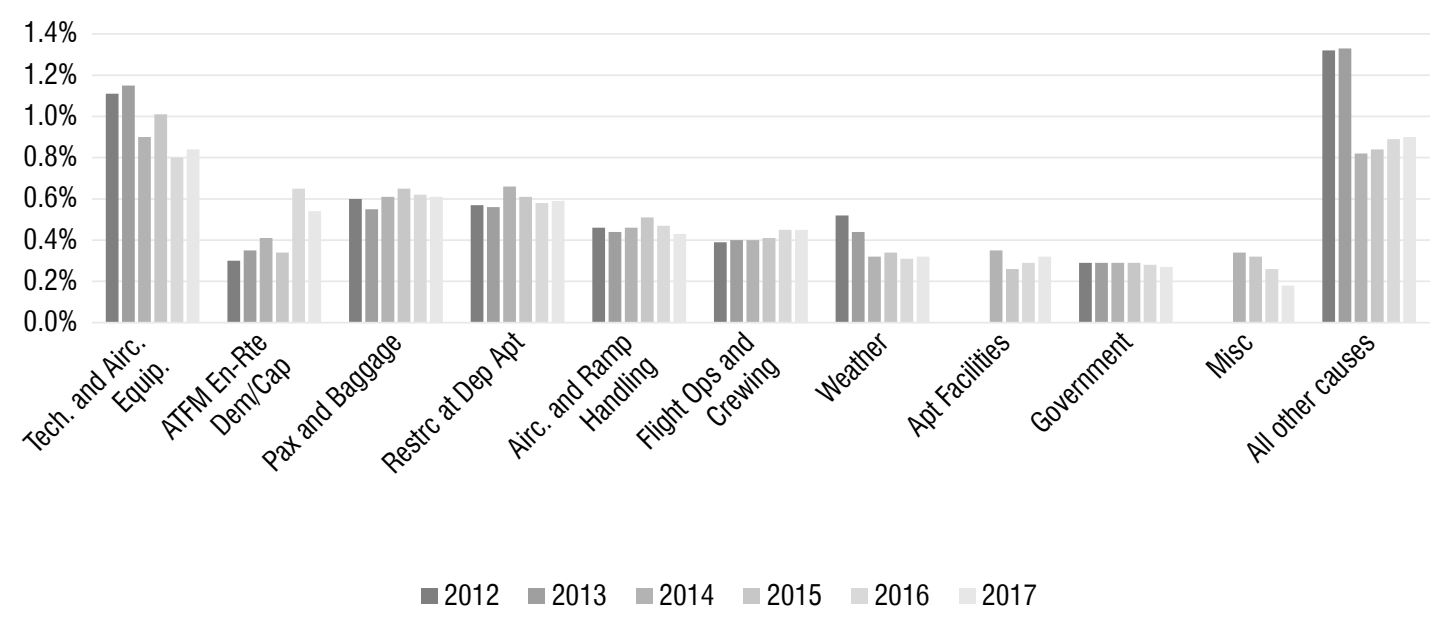

Source: Eurocontrol/CODA.

Figure 2. Average delay per flight in minutes by causes

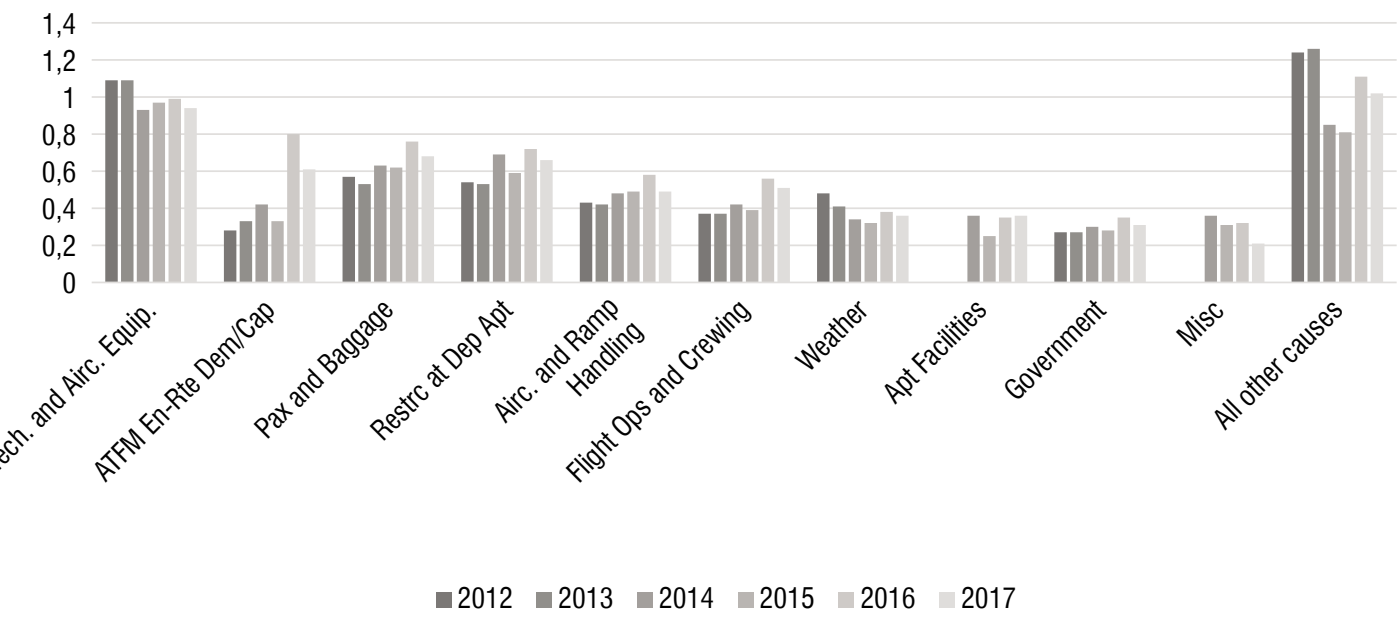

Source: Eurocontrol/CODA. 
When looking at the average shares of individual delay causes in the 2012-2017 period, aircraft and ramp handling is the fourth most common cause of delayed flights. On the other hand, the share of this category of delays has been declining since 2015 and in 2017 it was the sixth most common cause of delays. It should also be noted that the share of this category is relatively stable over time, with only two other categories being less variable (as indicated bythe standard deviation).

In terms of the absolute average delay, this downward trend in delays caused by ground handling operations is less visible, which should be attributed to a sharp increase in the total average delay in 2016. This skews the overall picture, depending on whether absolute or relative numbers are analysed. In relative terms, it can be concluded, however, that ground-handling-induced delays were somewhat contained over time when compared to other causes, which proves that in general other factors have higher potential of causing delays.

\section{Summary}

Ground handling operations are one of the key factors responsible for air traffic volatility, causing delays and disruptions to regular traffic patterns. However, data analysis showed that the share of ground-handling-induced delays was around 5 per cent in the 2012-2017 period and in recent years this share has been decreasing, while some other factors have been on the rise causing more and more delays. Despite this fact, ground handling is still responsible for a fair share of delays, making it a challenge to ground handlers, airlines and airports to cooperate in order to improve on-time performance. This cooperation must beparticularly intense as some current trends may adversely impact efforts to improve on-time performance. Ground handling service providers must also pay special attention to on-time performance at all stages of their operations.

\section{References}

1. Eurocontrol. ACDM Impact Assessment. Final Report, http://www.eurocontrol.int/sites/default/ files/publication/files/a-cdm-factsheet.pdf, [accessed: 11.04.2018].

2. Eurocontrol, http://www.eurocontrol.int/node/10666/library/cdm_brochure.pdf, [accessed: 11.04.2018].

3. Mayer C., SinaiT., 2003. Network Effects, Congestion Externalities, and Air Traffic Delays: Or Why Not All Delays Are Evil..American Economic Review, Vol. 93 (4 Sep).

4. Walker C., 2016. CODA DIGEST 2016, All-Causes Delay and Cancellations to Air Transport in Europe - 2016, Ed.No. CDA_2017_005, Eurocontrol,http://www.eurocontrol.int/sites/ default/files/content/documents/official-documents/facts-and-figures/coda-reports/codadigest-q4-2016.pdf, [accessed: 10.04.2018]. 
5. Wu W., Wu C.-L., Feng T., Zhang H., Qiu S., 2018. Comparative Analysis on Propagation Effects of Flight Delays: A Case Study of China Airlines..Journal of Advanced Transportation, Vol. 2018.

6. Zámková M., Prokop M., Stolín R., 2017. Factors influencing flight delays of a European airline. Acta Universitatis Agriculturae et Silviculturae Mendelianae Brunensis, Vol. 65, No. 5.

7. Zanin M., Belkoura S., Yanbo Z., 2017. Network analysis of Chinese air transport delay propagation. Chinese Journal of Aeronautics, Volume 30, Issue 2, April 2017. 
